\title{
EDITORIAL
}

\section{Call That A Bargain}

\author{
Curt Tribble, MD
}

Division of Thoracic and Cardiovascular Surgery, University of Virginia Health System, Charlottesville, Virginia, USA

\section{INTRODUCTION}

This life that I've led ... has took me everywhere.

There ain't no place I ain't never gone.

All I Can Do Is Write About It.

-Ronnie Van Zant

To paraphrase the lyrics of a song by Matchbox Twenty ("It's 3 AM, I must be lonely"), it's 3 AM, I must be on a Lear jet. We're heading out to get a pair of lungs for a transplant. It's pitch black out tonight, and there's light rain falling. At least it's not ice or snow, which we've heard is falling to the north of us. I am glad that we'll be heading south on this run. These organ procurement runs tend to violate one of the basic safety rules of flying: to avoid, whenever possible, being required to fly. The edgy flights tend to stick in one's mind, of course. I've flown, literally, into a hurricane (Isaac), slid around on icy runways in Michigan and New York, and landed at the same mountaintop airport that was featured in the movie "We Are Marshall" (which recounted the story of the fatal crash of a plane carrying Marshall University's football team back from a game in North Carolina).

I have one of my splendid surgery residents with me, and we settle in for the ride south. There'll be time for a nap, if I can get comfortable. However, I'm awake now, and I'm reminded of the overall mission that we are on. Inevitably, I find myself reflecting on my three decades of work as a transplanter of hearts and lungs, and recalling some of my most memorable patients and the lessons I have learned from them and their families. Memories and lessons that will always be with me.

\section{THE SHORT HAPPY LIFE OF RK}

Our business is not to see what lies dimly in the distance, but to do what lies clearly at hand.

- Thomas Carlyle

Early in my faculty tenure, over 30 years ago, my partner and I started first a heart transplant program, and then a lung transplant program, at our institution. In fact, we performed the first lung transplant in our state [Tribble 1991]. I directed both programs for years, and there were, of course, many sleepless nights. While heart transplantation was fairly well

Correspondence: Curt Tribble, MD, Professor of Cardiothoracic Surgery, University of Virginia Health System, Division of Thoracic and Cardiovascular Surgery, Box 800679, Charlottesville, VA 22908; 434-243-9250 (e-mail: CGT2E@bscmail.mcc.virginia.edu). established in those days, lung transplantation was earlier in its evolution. We were, fairly frequently, asked to consider transplanting children with failing lungs, such as those with cystic fibrosis, or children with pulmonary hypertension, such as those with congenital heart anomalies. However, the availability of donors for these children was limited. A surgeon in California whom I had known when I was a medical student was pioneering a program in which individual lobes of the lungs of living adult donors were transplanted into children, in order to overcome this shortage of donor lungs for children. We decided that we would follow the lead of this California team and set up a similar program.

One of the first patients we transplanted in this program was RK, a boy of about ten years of age, whose family lived in our region. RK had cystic fibrosis, and despite all the treatments that his pulmonologists had tried, he was on a trajectory that would likely lead to his death in the coming year or so. Therefore, we agreed that we would consider him for a bilateral lung transplant, if suitable donors could be found. Two men from the family's church volunteered to donate lobes for this boy, and a thorough workup revealed them to be suitable donors. We organized the three surgical teams necessary for this procedure, and despite concerns that we could conceivably end up with three mortalities for "one" operation, we pressed on. Our team was well prepared, both from the lessons and strategies shared by our colleagues and from practicing the procedure in our laboratory. When the appointed day of the transplant arrived, the procedures went along without a hitch. RK recovered quickly, as children often do, and soon went home with his new lungs and a bag of the medications needed to prevent rejection. Word of this unusual procedure got out, and he was invited, with his mother, to appear on a TV talk show which was filmed in New York.

The producers of the show sent a stretch limo to pick up RK and his mother at their house, which was, it turned out, fairly far off the beaten path in the Virginia mountains. As the story was told later, the limo was so long that it could not turn around at the end of their long driveway, and so the driver had to back all the way out to the main road, a distance that was said to be about a mile. RK and his family enjoyed regaling us with this tale. His appearance on the TV show was reported to be quite the adventure for him and his family.

RK returned to the hospital regularly for checkups, and for many months he seemed to be doing very well. About a year after his transplant, his family brought him in to see the lung transplant team that followed him. They reported 
that he had begun feeling tired and short of breath and then, recently, he had begun to cough up blood tinged sputum. This issue was immediately recognized as an ominous development. The chest $\mathrm{X}$-ray revealed that his lungs fields were hazy, when they had previously been quite clear. The ensuing workup revealed that he had a disseminated malignancy, which was subsequently found to be an unusual form of lymphoma. While malignancies in immunosuppressed transplant patients are not uncommon, they generally do not present so early after the transplant. Although our oncology colleagues instituted an aggressive chemotherapy regimen, to the dismay of all, the malignancy did not seem to respond to the treatment, and RK's condition deteriorated very rapidly. He never returned home, and died during that final hospitalization. All who had cared for him were devastated. The family returned home and we, of course, had to get back to our work.

About three weeks later, I was sitting on a bench in front of our hospital on a Friday evening. My wife was bringing a salad over to fuel me up for my usual 'Friday Night CatchUp' routine, in which I would try to get caught up on the inevitable backlog of computer and paper work that would build up during the week. The goal of this strategy was buying time for some weekend activities, should I be fortunate enough to not end up with too many chores during the weekend, which we enjoyed calling "a precious non-renewable resource."

As I sat in the warm evening air, I was startled to see RK's mother walking over from the parking garage, particularly so soon after her son's death. I asked her what she was doing returning to the hospital. She told me that she had gotten to know another boy, about RK's age, who also had cystic fibrosis and who was in our pediatric intensive care unit while RK was a patient there. She had learned that this boy was being raised by a single father, who was a Navy pilot stationed on the Virginia coast. In addition to this, she had gotten word that this boy's father had been called up for deployment overseas. She told me that she had returned to the hospital because "that boy needs a mother," and that she thought, "who would be better than me" to provide that support for the child. She saw the tears well up in my eyes, despite my best efforts to blink them away.

Understanding that my reaction to her amazing decision involved my own still-raw feelings about her son, she sat down to console me. She told me that she was at peace about her own son's final year of life, telling me how happy RK was to have been, for the first time in his life, a "real big brother" to his two younger brothers, running around with them in the woods, teaching them to play football, and helping them learn to ride their bikes. She told me that she viewed this time as a very happy one for him and their family that they would never have had without the transplant. As she stood to head up to the intensive care unit to take over "mothering" the sick little boy there, she thanked me for all our team had done to give RK the one year of his life when he was truly well and happy. I, of course, had to immediately recognize that I had no right to be sad for myself, nor for her or for RK, if she and her family were not going to be sad themselves.

\section{YOU GAVE US TIME THAT WE WOULD NEVER} HAVE HAD

Every surgeon carries within himself a small cemetery, where, from time to time, he goes to pray.

\section{-Rene Leriche}

A few years ago, I was riding my bike in the foothills of the Blue Ridge Mountains, literally within view of Skyline Drive, which runs along the crest of this range. As I rode through an idyllic valley, crossed a bridge over a small stream, and began to climb the hill on the other side of the stream, I realized that a pothole on the bridge had given my bike a flat tire.

There was no shoulder on this small, winding country road, but there was a church that sat on the top of the hill. Churches are often havens for road bikers because, other than a few hours a week, they're empty and have steps to sit on and parking lots that can be used for parking. I knew this route well, having ridden it many, many times, but I had never actually needed this particular church and its parking area before. As I got to the top of the hill, I saw that the graveyard surrounding the church had a fence that I could prop my bike against while I changed the tube in my tire. I leaned my bike against the fence, took off the wheel with the flat tire, and pulled out my spare tube. A pickup chugged over the hill below me, and I looked up at the beautiful spring sky and over at the mountains that I love. Distracted from my tire-changing chore, I looked over my shoulder and realized that I was sitting barely an arm's length from the grave of one of my all-time favorite patients, JR. An involuntary shudder ran through me, and I felt compelled to push my bike down the road a ways to finish putting the new tube in my tire at what seemed like a suitable distance from JR's grave.

I had about an hour left in my route, and as I rode on after the tube change, I reflected on the years-long saga of caring for this young woman. I had first met JR when she was in her mid-30's, when I was asked to do an urgent coronary artery bypass operation for her. We learned that she had lupus, which had likely led to her premature atherosclerotic disease. During the operation, we found that what had appeared to be coronary artery blockages on the catheterization films, which could be bypassed, was actually a diffuse disease that was not typical of coronary artery disease and was, rather, a diffuse narrowing of the vessels.

We constructed bypasses to each of the three main areas of her heart, but I knew, even then, that this revascularization was likely to be of only temporary benefit, at best. Indeed, my pessimism proved to be valid, as her clinical situation deteriorated within a few short years. We knew that we would need to do a heart transplant to have a chance of prolonging her life. By then, we knew that she was married to a wonderful man and that they had two little boys. In addition, though I did not know it at first, it turned out that I had also operated on her mother some years earlier. We eventually did find a donor for JR, and performed a successful transplant. We hoped that the immunosuppression required for the transplanted heart would also have a beneficial effect on her lupus. 
Unfortunately, the lupus, perhaps in conjunction with her immunosuppressive medications, took a toll on her kidneys, eventually necessitating a kidney transplant about five years after her heart transplant. Her dedicated husband was the donor of that kidney. By this time, their boys were entering their early teens. In the ensuing years, she underwent regularly scheduled coronary angiograms. We realized that the arteries of her new heart were gradually narrowing, perhaps from a combination of her lupus and the fairly common coronary vasculopathy, which is often seen in heart transplant patients and is thought to be the result of chronic rejection.

Eventually, we realized that her coronary artery blockages had progressed to a point where something needed to be done, either a coronary artery bypass operation, or perhaps, another heart transplant. With the well-known chronic shortage of donor hearts in the minds of our team, and with some of the blockages in her arteries appearing to be focal blockages, our team concluded that an attempt at performing a coronary bypass operation was warranted. Everyone involved knew that this approach would carry a high risk, but the consensus was that this operation was the appropriate strategy. By this time, her boys were in their later years of high school.

\section{We're all going to die. Some just have more information than others. -Kate Bowler}

The operation proved to be surprisingly more like her first coronary artery bypass operation than we had expected. The coronary arteries that we had thought would have blockages focal enough to permit them to be bypassed proved much more diffusely diseased than we had hoped. We did attempt to construct bypasses to these arteries, but, to our chagrin, the bypasses were not effective, and her heart did not work well enough to wean from the bypass machine at the end of the case. While we utilized several sequential forms of circulatory support, we soon realized that further support would be futile and the mechanical support was withdrawn.

While we realized that this outcome was profoundly moving for all involved, we had to at least try to comfort ourselves and the family by acknowledging that this situation was sad, but perhaps not tragic. Through the efforts of all concerned, we had kept her alive to see her boys grow from childhood to early adulthood. JR had known throughout the course of her adulthood that she was not destined to live a long life. Therefore, she and her family had made the most of the time that had been given to her.

In reflecting on JR's life after we first met her, I reminded myself that everyone in the equation knew that she was not going to live a long life. We did believe, however, that if we could add years to her life, we would have helped her stay alive long enough for her boys to make it through childhood. We always tried to be realistic, but also to retain hope that we could accomplish the outcome that we eventually achieved. I believe that everyone involved did consider the eventual outcome sad, but not tragic. In this protracted span, there was always a "ripple of hope," right up until the very end.
JR's life reminds me of a song by the band Storyhill called "Blazing Out of Sight." When I hear this song, the last verse particularly reminds me of her:

$$
\begin{gathered}
\text { It's in the deep unknowable blue } \\
\text { Of the silent night sky } \\
\text { It's not being able to talk to you } \\
\text { And not knowing why } \\
\text { Maybe knowing we'd never make it } \\
\text { Made it so right } \\
\text { Shooting stars burn the brightest } \\
\text { We were meant to be blazing out of sight }
\end{gathered}
$$

When I ride my bike by JR's grave now, I always stop to visit. I am not sad now, knowing that she, and all of us who cared for her, did the very best we could with the difficult hand we were dealt, and we were able to give her and her family time that they otherwise would not have had.

\section{BETTER TO HAVE LOVED AND LOST, THAN TO HAVE NEVER LOVED AT ALL?}

I hold it true, whate'er befall,

I feel it when I sorrow most,

'Tis better to have loved and lost,

Than never to have loved at all.

—Alfred Lord Tennyson, In Memoriam A.H.H.

One dark and stormy night about 25 years ago, I got a call from my favorite pediatric cardiologist, whom I had known since she was a medical student. She had a challenging request to make of me. My partner, who was out of town, had operated on an infant for congenital stenosis of the aortic valve when the child was but a few days of age, and this now one month old baby was dying of heart failure. Amazingly, there was another baby of about the same age in our hospital whose parents had consented that day to donate his organs for transplantation after a declaration of brain death. She told me that she had just learned that the designated transplant team would not be able to come to procure the heart of this child because of the severe weather.

She was aware that, although I had logged an adequate number of congenital cardiac cases as a resident, in the years that followed I had not been performing congenital cardiac surgery. However, in her usual matter-of-fact style, she informed me that both babies would almost certainly die that night, unless I would be willing to procure the heart from the tiny donor and to implant it into the child that had had the unsuccessful operation on his aortic valve. While there was no doubt that this proposed procedure was a bit out of my comfort zone, it was hard to argue with her request to at least attempt to save this baby's life. Thus, I agreed to give it a try.

We rounded up a good team that night, with an experienced pediatric cardiac anesthesiologist and a senior cardiac surgical resident, along with all the others needed for these procedures. While the babies were being moved to adjacent operating rooms, I was able to grab a cup of coffee, knowing the night would be a long one. As I took my first sip, I got a call from the anesthesiologist, saying that the baby with the failing heart was so edematous that he had not been able to insert an arterial line. He asked me to come to do an open procedure to try get one of these lines inserted. When 
I arrived in the operating room, I was startled by how swollen the baby was. I was not optimistic that I would be able to find a suitable artery for a monitoring line, but I knew I had to try.

I rounded up the appropriate gear, got out my magnifying loupes, and sat down beside the baby to attempt a cut down on his left groin, hoping to find his femoral artery. When I made my initial incision, edema fluid literally gushed out of the incision. I saw no familiar structures. We blotted and squeezed the thigh around this incision, hoping to see some familiar structures, to no avail. I worked my way down into the incision and, eventually, saw a linear structure, which seemed to have at least some chance of being a vascular structure, though it didn't really look like it was an artery.

I asked someone to find me the tiniest vascular catheter available. I knew that if I were able to cannulate this structure, and if we had an arterial waveform when the catheter was hooked to a monitor, it would be nothing short of a miracle. I inserted the catheter as precisely as I thought possible and hooked it to the monitor. Even to this day, I get chills remembering seeing a normal arterial trace appear. I have often thought that getting this arterial line to work was as close to a miracle as anything I have experienced in my career.

From that point, procuring the heart from the donor and implanting it into the recipient went along according to plan. The transplanted heart worked very well, and after closing up, we moved the baby with his new heart back to the pediatric intensive care unit. He recovered uneventfully and was able to go home a couple of weeks after his operation. While none of us who had participated in this transplant dwelt on the long term prognosis, we knew, as did the family, that the average survival time of patients with transplanted hearts averages about ten years. However, we also recognized that we could not anticipate what we might be able to do for such patients in the future.

\section{Don't skip to the end. \\ -Kate Bowler}

Though I myself did not follow this child after his transplant, I would receive updates, including pictures, from my pediatric cardiology colleagues who were his primary doctors and who saw him regularly. There were pictures of his graduation from kindergarten, complete with a cap and gown, and other activities such as playing on his soccer team. Pictures such as these are some of my greatest treasures, and I have routinely solicited them from patients and families throughout my career [Newburg 2017; Tribble 2016].

One day, which in retrospect was indeed about ten years after we performed this transplant, I got an urgent call from my pediatric cardiology colleague. She was in the emergency room where they were trying to resuscitate our patient, who had suffered a cardiac arrest. She said she knew that we had little to offer in this situation, as this all unfolded well before we had mechanical circulatory support suitable for children. While in the moment, we did contemplate trying to rig up some sort of circulatory support, we all knew that the saga would almost certainly not end well, and the difficult decision was made to stop the resuscitation. We tried to find some solace by remembering that we had given this child and his family ten relatively good years together.

\section{I'd gladly lose me to find you. I'd gladly give up all I had. \\ To find you I'd suffer anything and be glad. \\ I'd call that a bargain, the best I ever had. \\ -Pete Townsend and The Who}

Some years later, I ran across an essay in which the author recounted an attempt to console a friend whose teenaged son had recently died in an automobile accident. The writer noted that he had found himself asking his friend this question: "If God had made you an offer to 'lend' you your son for about 20 years with the provision that, at the end of that time, He would call him home, would you have accepted that offer?" While I do not recall what the writer said the father's answer to that question was, the concept was certainly thought provoking.

I have, on a few occasions, found myself recounting that story to friends who had lost a child under similar circumstances, in hopes of providing an idea that might provide some solace. In each of those occasions, my friends have told me later that it did indeed provide some comfort, saying that they thought that they would have indeed accepted that bargain. When thinking of this concept, I have often wondered what the parents of the little boy we transplanted would have said had we posed a similar question to them the night we did his transplant. Would they themselves have accepted that bargain? I think I myself would have, and I would like to think that, even in retrospect, these parents would have as well.

\section{CONCLUSION: WHAT I LEARNED OUT ON THE} ROAD

From Detroit to New Orleans,

I've loved the life, but I never sold my soul.

All them late nights and early mornings,

Let me tell you what I learned out on the road.

-Robert J. Ritchie (AKA, Kid Rock)

We are back in our Lear jet now, preparing for the ride back home with the lungs we had procured. The pilots, as usual, have rounded up some food for us, and we will power it down as we prepare for takeoff, as it's often hard to eat in the turbulence we regularly encounter. The sun is rising, and it's hard not to think of the parallel between a sunrise and our mission to bring a renewal of life to the recipient of the organs we have procured. Still, I also regularly reflect on the transient nature of life in general, and in particular for our transplant recipients. Today will be no exception. We have the capacity, or even the requirement, that we focus on this "resetting of the clock" for our patients, and acknowledge the reality that this reset will inevitably be a relatively temporary one. I also find myself reflecting on the ways that all in medicine can ward off or 
deal with the inevitable disappointments and losses that we must deal with.

Between stimulus and response there is a space. In that space is our power to choose our response. In our response lies our growth and our freedom.-Viktor Frankl

\section{Burnout and Emotional Exbaustion}

The medical literature and the lay press are currently replete with reports of depersonalization, burnout, and emotional exhaustion among physicians and other health care providers. While there are many issues that are described as contributing to this state of affairs, one frequently discussed challenge is dealing with the deaths of patients. In fact, some clinicians, such as oncologists, have been found to experience grief over patient loss that includes a sense of sadness, guilt, and personal responsibility, which has an impact on their personal and professional lives. [Granek 2012].

However, my patients and their families, especially as illustrated by the three stories that have come to mind on this particular day, provide a different perspective on some of these issues. Thus, I have found that stories such as these of heroic patients and their families can, and should, serve as sources of inspiration for all involved in their care.

\section{Sad but not Tragic}

One of the concepts I have learned from our patients is that we all must recognize that life is a limited-time offer, and that we are all living on borrowed time. These principles have never been more evident to me than in experiences like these from my career in transplantation. While we know that transplanting an organ gives a patient extra time, we also know that we

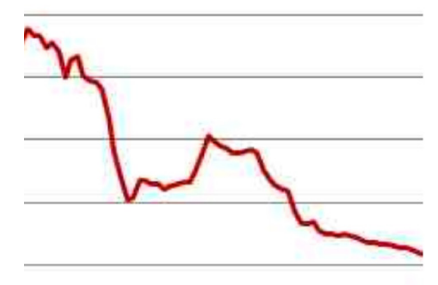

Figure 1. A graph representing a transplanted patient's life span versus that patient's quality of life. The transplant itself interrupts and resets the decline in quality of life, but the decline in quality of life begins anew eventually, a reality of which all involved are aware.

are always trading one disease for another, while hoping to at least reset the "life clock" of the patient. However, this is done without any guarantee of how much time will have been gained for any given patient. As all physicians know, we must celebrate the improved quality of life that may be afforded by any medical or surgical intervention, hoping that the amount of added time is considerable but realizing that all care, including transplantation, is palliative but not curative. We must also recognize that, when the lives of our transplanted patients do come to an end, it is often sad but not always tragic [Tribble 2017b] [Figure 1].

\section{A Ripple of Hope}

Fust to find tomorrow, one more day, I'd be amazed.

Fust to see it waiting, and if I make it, I'm still alone.

No more bope for better days, but if I could change,

Then, I'd really be amazed.

-The Offspring, Amazed

One of my grandfathers was a Presbyterian minister, and he ended every letter that he wrote with these words: "In Hope." I never asked him why he chose to use this closing for his letters and notes. Why not "With Love," or "In Faith," both of which one might think a "man of the cloth" might prefer? However, hope can indeed be a powerful aid in life, and all involved in health care need to protect it for our patients. Roger Bone, a physician dying of metastatic renal cancer, wrote in an essay entitled "Benediction: A Farewell to my Medical Colleagues," that he had learned "the importance of hope even in the face of impossible odds." He went on to note that he had "learned... that acceptance and denial can coexist," and that "as physicians we must never give our patients false hopes or unrealistic expectations. But neither should we deny them the comfort that hope can bring" [Bone 1997]. Additionally, virtually everyone in medicine is familiar with Elisabeth Kubler-Ross's writings about the stages of grief, the last two stages of which are acceptance and hope.

\section{Friendship and Concern}

The elderly bealers with whom we talked were quiet, simple, strong, and sure. They work with neighbors and neighbors' children individually, when asked to help, and they respond as a gesture of friendship and concern.

\section{—The Foxfire Book. Eliot Wigginton}

Fifty years ago, a teacher assigned to work with underprivileged students in southern Appalachia had his students interview their families and neighbors and record their conversations as a way of helping these students improve their language and writing skills. The transcribed interviews were later collected in a series of books called "The Foxfire Books." The description of how these faith healers "responded as a gesture of friendship and concern" can serve as a guide to all health care practitioners. And, if that care has been given with friendship and concern, the providers should allow themselves to find solace, regardless of the outcomes achieved. As an old saying goes, "the only miracles are the ancient ones of friendship, loyalty, and love" [Wigginton 1972].

\section{An Ordeal of Grandeur}

It is as if the wind were trying to warn me that I am to undergo an ordeal, that my voyage will not be an idyll. But I bave, I bope, no illusions. I expect an ordeal, an ordeal of grandeur.

—Webb Chiles, Storm Passage

In his account of his solo circumnavigation of the globe in a sailboat, Webb Chiles notes that, while he expects his voyage to be an ordeal, he expects it to be an "ordeal of grandeur." I have often thought of this passage, particularly in dealing with the inevitable highs and lows of a life in surgery and, particularly, in transplantation [Chiles 1977]. 
The way of life that I preach is... the practice of living for the day only, and for the day's work: life in day-tight compartments... The quiet life in day-tight compartments will belp you bear your own and others' burdens with a light heart.

- Sir William Osler, A Way of Life

Osler's admonition has much to recommend it, not just to the physicians of his day, but to modern practitioners as well. While the phrase "day-tight compartments" may seem a bit archaic, the concept is timeless. One must be able to compartmentalize not just the information related to specific patients or situations, but also one's own emotions about those situations. As Dr. Osler noted, one should "undress your soul at night... and you will wake a free man, with a new life." Those practitioners who find themselves unable to always adhere to Dr. Osler's advice, perseverating on a clinical situation that they have been unable to completely control, can at least find some solace by acknowledging that they have followed the advice given by Bob Seger in one of his most popular songs, "every ounce of energy you try to give away," acknowledging that they have indeed done all that they can do. [Osler 2010]

\section{We Have No Choice but to Carry On}

One morning I woke up and I knew that you were gone.

A new day, a new way, and new eyes to see the dawn.

Go your way, I'll go mine and carry on.

The sky is clearing and the night has cried enough.

The sun, be come, the world to soften up.

Rejoice, rejoice, we have no choice, but to carry on.

-Crosby, Stills, \& Nash, Questions of a Thousand Dreams

At the end of the day, we, too, as this old song says, have no choice but to carry on. The next patient and the next family will need our undivided attention, and they will need us to be at our best for them.

\section{Memories that Make Us Wealthy Souls}

Sometimes at night, I see their faces.

I feel the traces they left on my soul.

Those are the memories that made me a wealthy soul. Yes, those are the memories that made me a wealthy soul. -Bob Seger
In summary, we would do well to remember these words from Bob Seger's song, "Travelin' Man." In this song he sings of how people, our patients in our case, will leave memories that, on balance, make us wealthy souls. And, perhaps, the proper focus on these memories will provide at least some defense against the burnout that is so prevalent in health care providers today. The privilege of caring for patients is indeed a bargain, the best I've ever had.

\section{ACKNOWLEDGEMENT}

I would like to acknowledge the lessons and the inspiration that my patients and their families, especially those whose stories I have discussed here, have provided me in my four decades in clinical medicine. The initials used to describe the patients I have described are not their real initials.

\section{REFERENCES}

Bone, R. 1997. Benediction: a farewell to my medical colleagues. J Crit Ill 12:439-40.

Bowler K. 2018. Everything Happens for a Reason: And Other Lies I've Loved. Random House, New York.

Chiles W. 1977. Storm Passage. Crown Publishing Group.

Granek L, Mazzotta P, Tozer R, et al. 2012. What do oncologists want? Suggestions from oncologists on how their institutions can support them in dealing with patient loss. Support Care Cancer 20:2627-32.

Newburg D, Tribble C. 2017. Give my poor heart ease. Heart Surg Forum 20:1-4.

Osler W, Twain C. 2010. A Way of Life (In Today's English). ReadaClassic.com.

Tribble C, Kern J, Findley L, et al. 1991. The first single lung transplant in Virginia. Va Med Q 118:166-7.

Tribble C. 2016. Gimme 3 steps. Heart Surg Forum 19:1-2.

Tribble C. 2017. Grandmother rules: crucial conversations with patients and families. Heart Surg Forum 20:1-5.

Tribble C. 2017. Knockin' on heaven's door: end of life decisions and discussions. Heart Surg Forum 20:1-5.

Wigginton E. 1972. The Foxfire Book. First Anchor Books. 